\title{
Ustawiczny częstoskurcz komorowy z komisur płatków aortalnych lewowieńcowego i niewieńcowego*
}

\author{
Sustain ventricular tachycardia originated from left coronary \\ and noncoronary aortic cusps
}

\author{
Przemysław Stanisław Dąbkowski ${ }^{1}$, Maciej Młodnicki ${ }^{1}$, \\ Paweł Wałek ${ }^{1}$, Beata Wożakowska-Kapłon ${ }^{1,2}$ \\ ${ }^{1}$ I Klinika Kardiologii i Elektroterapii Świętokrzyskiego Centrum Kardiologii w Kielcach \\ ${ }^{2}$ Wydział Lekarski i Nauk o Zdrowiu Uniwersytetu Jana Kochanowskiego w Kielcach
}

\section{Streszczenie}

Przedstawiono przypadek 68-letniego pacjenta z ustawicznym częstoskurczem komorowym, opornym na leczenie farmakologiczne, obciążonego licznymi schorzeniami układu sercowo-naczyniowego. Chory był po wymianie zastawki mitralnej i zespoleniu tętnicy piersiowej wewnętrznej do tętnicy przedniej zstępującej, z utrwalonym migotaniem przedsionków i niewydolnością serca z pośrednią wydolnością skurczową lewej komory. W pracy opisano diagnostykę krok po kroku oraz sposób postępowania inwazyjnego u pacjenta obciążonego licznymi czynnikami ryzyka zdarzeń sercowo-naczyniowych.

Słowa kluczowe: ustawiczny częstoskurcz komorowy, mapowanie, leczenie przeciwkrzepliwe, ablacja

Folia Cardiologica 2018; 13, 1: 64-69

\section{Opis przypadku}

Chory w wieku 68 lat, z wieloletnim wywiadem choroby niedokrwiennej serca, po implantacji sztucznej zastawki mitralnej oraz po pomostowaniu w postaci zespolenia tętnicy piersiowej wewnętrznej do tętnicy przedniej zstępującej (LIMA-LAD, left internal mammary artery to left anterior descending coronary artery), z utrwalonym migotaniem przedsionków i niewydolnością serca, został przyjęty na oddział intensywnego nadzoru kardiologicznego (OINK) po zaistniałym w domu zasłabnięciu bez utraty przytomności. Dolegliwości pojawiły się bez związku z wysiłkiem fizycznym, stresem, emocjami czy alkoholem i nie towarzyszyły im objawy dławicowe ani infekcja.
W elektrokardiogramie (EKG) wykonanym na oddziale pomocy doraźnej oraz w kolejnych zapisach EKG wykonanych na szpitalnym oddziale ratunkowym (SOR) oraz OINK szpitala wojewódzkiego stwierdzono ustawiczny częstoskurcz komorowy (VT, ventricular tachycardia) z rytmem komór 180-200/min o morfologii: prawogram z blokiem lewej odnogi pęczka Hisa (LBBB, left bundle branch block). Powrót rytmu zatokowego uzyskano po dożylnym (i.v., intravenous) podaniu $300 \mathrm{mg}$ amiodaronu. W wykonywanych kontrolnych badaniach EKG stwierdzono obecność mnogiej arytmii komorowej o morfologii zgodnej z VT (ryc. 1B).

U chorego wystąpił już przed 2 laty, jak ustalono w wywiadzie, niestabilny VT, który ustąpił po leczeniu farmakologicznym w szpitalu rejonowym.

\footnotetext{
*Praca powstała w ramach realizacji projektu: „Zakup wyposażenia I Klinicznego Oddziału Kardiologii i Pracowni Elektrofizjologii szansą na zwiększenie innowacyjności Wojewódzkiego Szpitala Zespolonego w Kielcach” współfinansowanego przez Unię Europejską ze środków Europejskiego Funduszu Rozwoju Regionalnego w ramach Regionalnego Programu Operacyjnego Województwa Świętokrzyskiego na lata $2007-2013$
}

Adres do korespondencji: lek. Przemysław Stanisław Dąbkowski, I Klinika Kardiologii i Elektroterapii, Świętokrzyskie Centrum Kardiologii, ul. Grunwaldzka 45, 25-736 Kielce, e-mail: pp.dab@wp.pl 


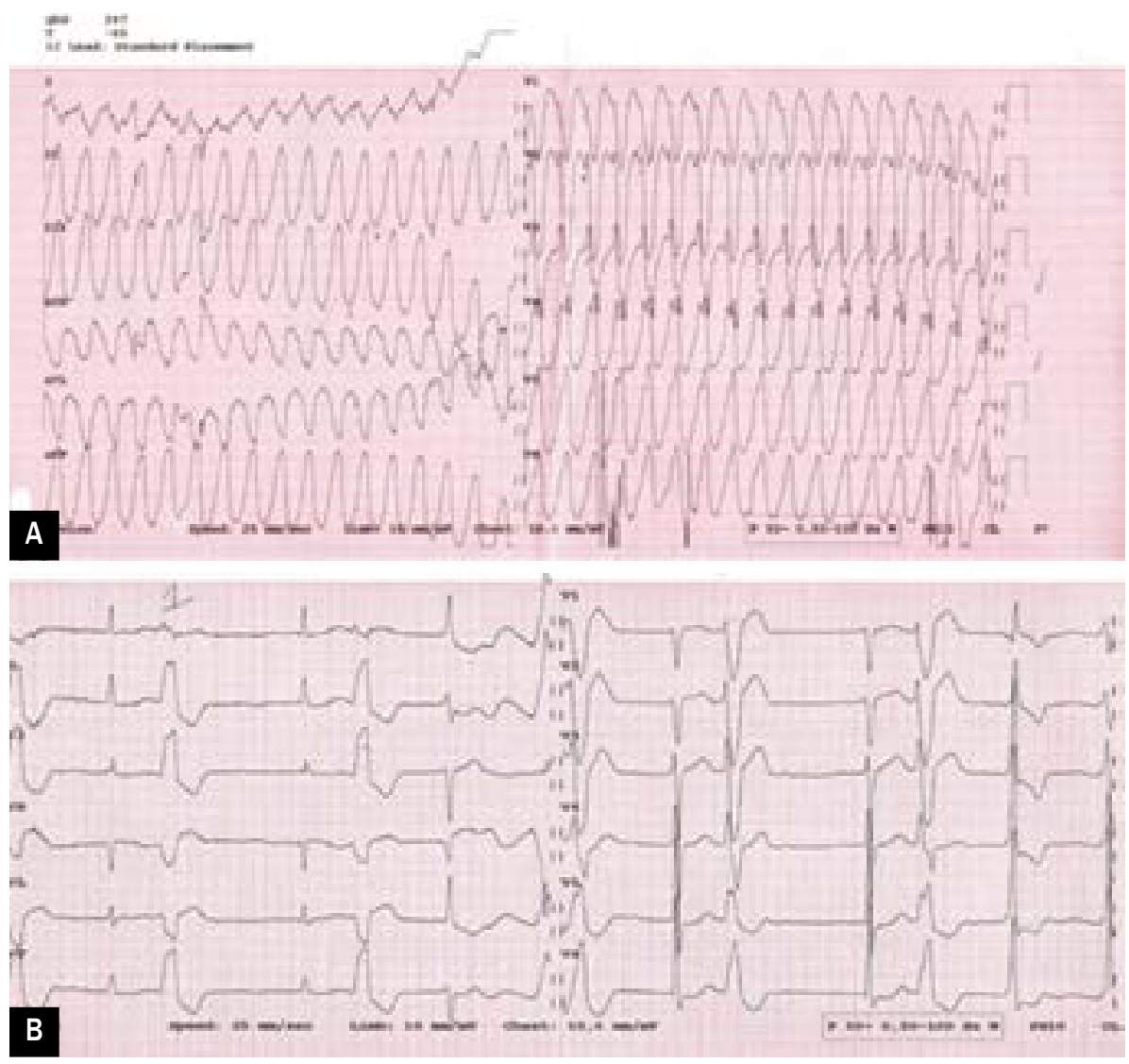

Rycina 1A. Zapis elektrokardiograficzny (EKG) przedstawiający częstoskurcz komorowy (VT, ventricular tachycardia) o częstości rytmu komór 198-200/min, o morfologii: prawogram z blokiem lewej odnogi pęczka Hisa; B. W kontrolnym badaniu EKG stwierdzono obecność mnogiej arytmii komorowej o morfologii zgodnej z VT

W badaniach dodatkowych wykonanych w warunkach OINK stwierdzono prawidłowe parametry morfologii, badań biochemicznych i prawidłowe stężenia markerów martwicy miokardium, poza nieznacznie podwyższonym stężeniem troponin. Z kolei w badaniu echokardiograficznym uwidoczniono poszerzenie jam serca lewego (lewy przedsionek [LA, left atrium] $70 \mathrm{~mm}$, lewa komora [LV, left ventricle] 70/63 mm) z uogólnioną hipokinezą mięśnia LV i frakcją wyrzutową lewej komory (LVEF, left ventricular ejection fraction) około $20 \%$.

Po ustabilizowaniu stanu klinicznego pacjenta przeniesiono w celu dalszego leczenia na oddział kardiologii. Tam w wykonanych badaniach EKG zarejestrowano pojedyncze dodatkowe pobudzenia komorowe o trzech morfologiach (ryc. 2). Natomiast w 24-godzinnym monitorowaniu EKG metodą Holtera stwierdzono utrwalone migotanie przedsionków z maksymalną częstością rytmu komór 124/ /min oraz średnią 83/min i minimalną 59/min. Ponadto zarejestrowano 99 dodatkowych pojedynczych pobudzeń komorowych oraz jedną pauzę R-R wynoszącą 2,7 s.

W kontrolnym badaniu echokardiograficznym wykonanym $w$ trakcie pobytu chorego na oddziale kardiologii stwierdzono poprawe LVEF do około 50\%, zmniejszenie wymiarów LV do $58 \mathrm{~mm}$ w rozkurczu oraz prawidłową funkcję sztucznej zastawki mitralnej. W kolejnych dobach hospitalizacji nastąpiły nawrót VT o morfologii zgodnej ze stwierdzaną przy przyjęciu do szpitala oraz pogorszenie stanu ogólnego pacjenta. Choć zintensyfikowano leczenie farmakologiczne (leki beta-adrenolityczne oraz amiodaron i.v.), to nie udawało się wygasić arytmii. Mimo częstości rytmu komór w zakresie 170-180/min pacjent dość dobrze tolerował częstoskurcz (ciśnienie tętnicze 115-120/70 mm Hg); nie występowały cechy dekompensacji układu sercowo-naczyniowego ani objawy dławicowe.

Z powodu przebytej wymiany zastawki mitralnej (MVR, mitral valve replacement) $w$ diagnostyce różnicowej pomiędzy atypowym lewostronnym trzepotaniem przedsionków a VT u pacjenta z LBBB podano dożylnie 12 mg adenozyny, nie uzyskując jednak przerwania przewodzenia w łączu, co jednoznacznie wskazywało na komorowe pochodzenie arytmii. Jedynym efektem działań było nieznaczne zwolnienie częstości VT. Częstoskurcz wykazywał również ograniczoną wrażliwość na próbę Valsalvy - umiarowienie trwało kilka sekund, po czym pojawiały się przedwczesne skurcze komorowe (PVC, premature ventricular contraction) o morfologii zgodnej z VT, a potem ponownie częstoskurcz (ryc. 3B).

Wobec tak opornej na leczenie farmakologiczne arytmii zdecydowano o przeprowadzeniu zabiegu ablacji w trybie 


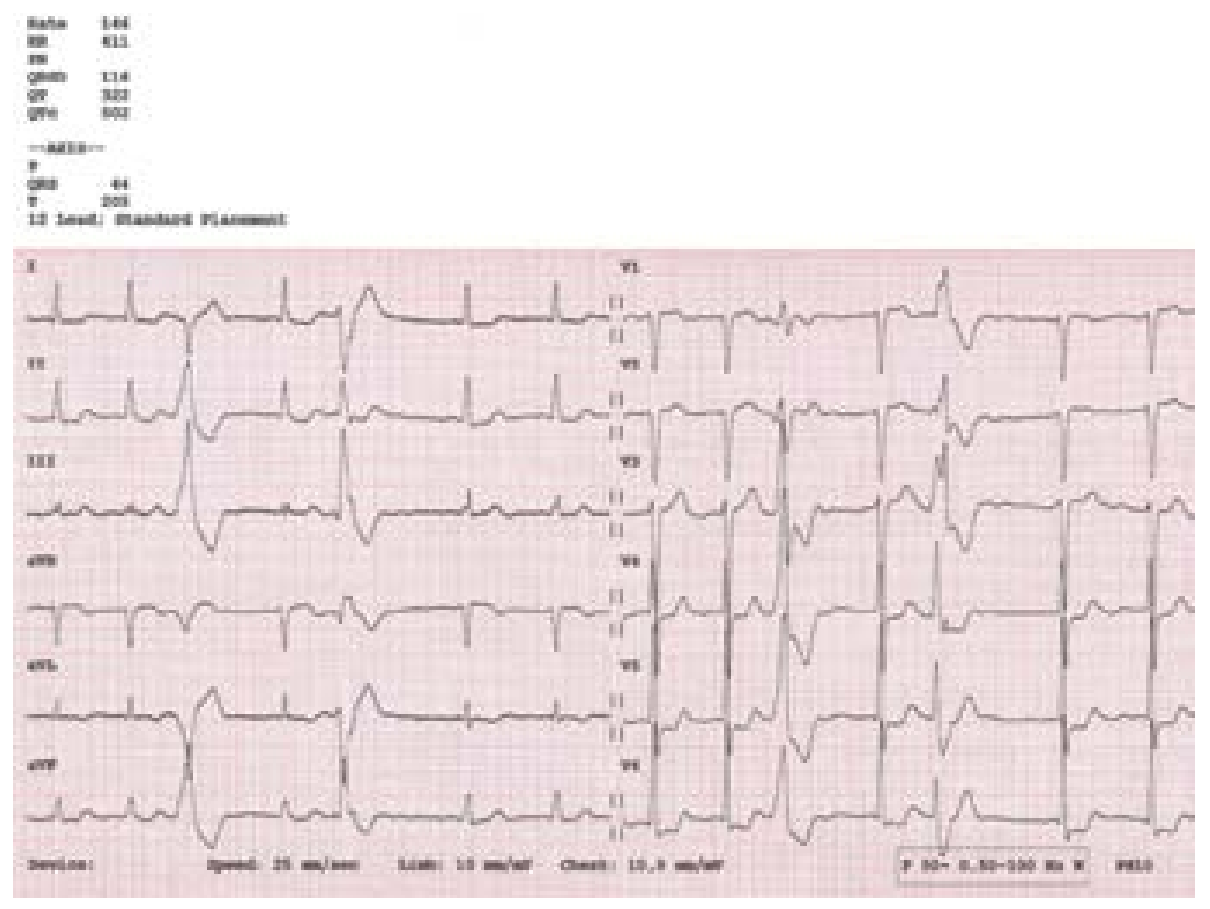

Rycina 2. Zapis elektrokardiograficzny przedstawiający przedwczesne skurcze komorowe o innej morfologii niż w klinicznym częstoskurczu komorowym, o morfologii: prawogram z blokiem prawej odnogi pęczka Hisa

przyspieszonym. Przy użyciu systemu elektrofizjologicznego Lab System Pro firmy Boston Scientific oraz systemu elektroanatomicznego 3D Carto3 wykonano mapowanie, a następnie skuteczną ablację ustawicznego VT. Po założeniu elektrody Response JSN z dojścia szyjnego do zatoki wieńcowej (CS, coronary sinus) oraz elektrody Supreme do prawej komory (RV, right ventricle) ostatecznie potwierdzono komorowy charakter arytmii, obserwując w zapisach obraz rozkojarzenia przedsionkowo-komorowego. Jako elektrodą mapującą posłużono się elektrodą Thermocool SF Smart Touch firmy Biosense Webster o krzywiźnie D-F. Początkowo zmapowano drogę odpływu z prawej komory (RVOT, right ventricle outflow tract) oraz okolice zastawki pnia płucnego, uzyskując w mapie aktywacyjnej systemu Carto3 najwcześniejszą aktywację w okolicy przyśrodkowej RVOT. Maksymalne wyprzedzanie wynosiło tutaj $25 \mathrm{~ms}$ na elektrodzie ablacyjnej w systemie Lab Pro. W tej okolicy wykonano kilka aplikacji energii prądem o częstotliwości radiowej (RF, radiofrequency), o mocy od 20 do ponad $30 \mathrm{~W}$, ale - mimo zachęcających parametrów - arytmia nie ustapiła (ryc. 4). Zdecydowano o kontynuowaniu zabiegu po lewej stronie i wybrano dojście wsteczne przez zastawkę aorty. Niestety, podczas wkłucia do tętnicy udowej okazało się, że występują w niej zaawansowane zmiany miażdżycowe, a tętnica biodrowa ponad więzadłem pachwinowym odchodzi w górę zgięta pod kątem 90 stopni (ryc. 5). Do pokonania tego zakrętu, a także by poprawić manewrowalność elektrodą ablacyjną, operatorzy musieli użyć zbrojonej koszulki dotętniczej firmy Arrow $65 \mathrm{~cm}$ 9F. Za jej pomoca uzyskali odpowiedni dostęp do okolicy opuszki aorty i jej płatków. Między płatkiem lewowieńcowym a niewieńcowym zarejestrowano potencjały wyprzedzające na elektrodzie ablacyjnej zespoły QRS VT o $50 \mathrm{~ms}$. (ryc. 6A).

W odprowadzeniu unipolarnym rejestrowano typowy potencjał ,uniW". Na obu systemach, tj. zarówno elektrofizjologicznym, jak i Carto3, potwierdzono również zgodność morfologii arytmii z zarejestrowanym wzorcem okresowo pojawiających się w zapisach EKG pojedynczych PVC. Ze względu na bliskość pnia lewej tętnicy wieńcowej wykonano aortografię, lokalizując jego ujście. Przystąpiono do aplikacji energii RF, stopniowo zwiększając wartość z 15 do ponad $30 \mathrm{~W}$, i po trzech aplikacjach uzyskano całkowite ustapienie arytmii (ryc. 6B). Po około 20 minutach obserwacji wykonano programowaną stymulację komór zgodnie z protokołem 500-3 z elektrody Supreme, uzyskując ponowną indukcję VT o morfologii zgodnej z wyjściową. Następnie wykonano aplikacje konsolidujące w miejscu poprzednich oraz ich najbliższym sąsiedztwie, co spowodowało trwałe ustąpienie arytmii. Po około 20-minutowym okresie obserwacji ponownie wykonano programowana stymulację komór według protokołów jednym, dwoma i trzema impulsami dodatkowymi (400-1/400-2/400-3) - wszystkie do refrakcji komory i braku indukcji VT. Początkowo zachęcające wartości wyprzedzania w RVOT oraz obraz mapy aktywacyjnej w systemie Carto3 można tłumaczyć bliskim sąsiedztwem obu struktur, co wyraźnie widać po nałożeniu na siebie obu map z zaznaczonymi punktami ablacyjnymi (ryc. 7). 
Przemysław Stanisław Dąbkowski i wsp., Ustawiczny VT z komisur płatków aortalnych lewo- i niewieńcowego

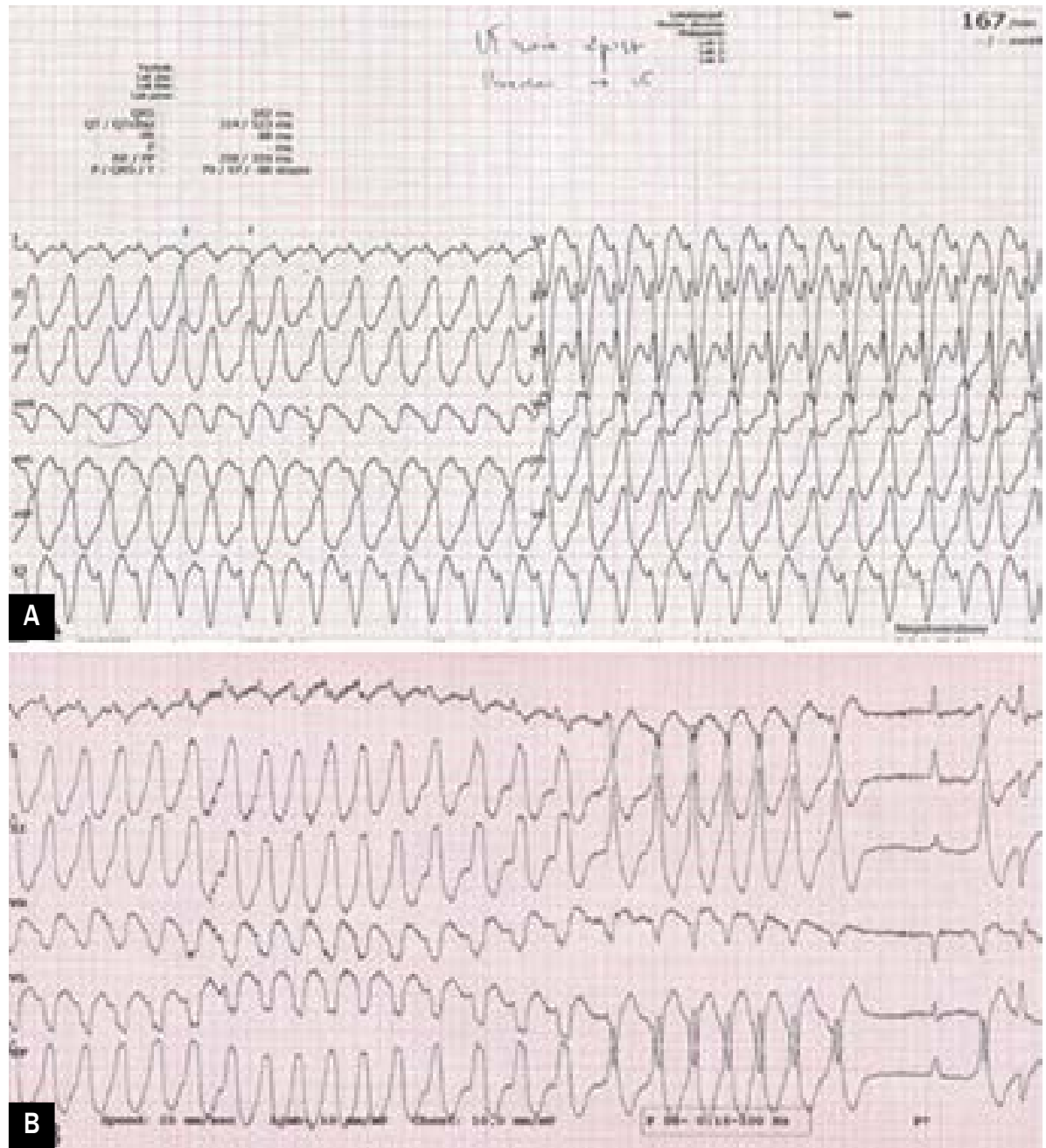

Rycina 3A, B. Zapis elektrokardiograficzny: A. Nawrót klinicznego częstoskurczu komorowego (VT, ventricular tachycardia); B. Ustępowanie VT w reakcji na próbę Valsalvy

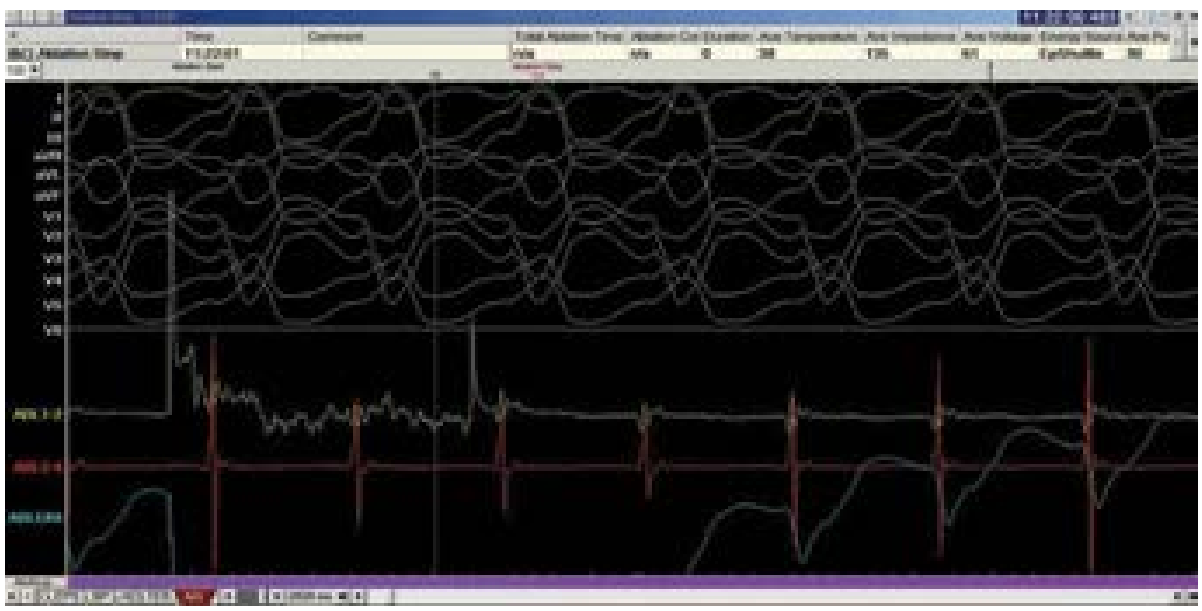

Rycina 4. Nieskuteczne aplikacje energii prądem o częstotliwości radiowej (RF, radiofrequency) w drodze odpływu z prawej komory 


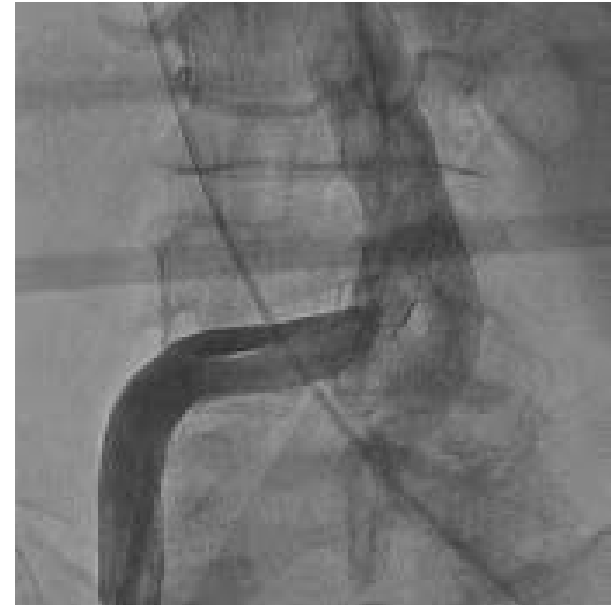

Rycina 5. Angiogram prawej tętnicy biodrowej
W trakcie kilkudniowej obserwacji pacjent nie odczuwał arytmii; w wykonywanych seryjnie badaniach EKG obserwowano pojedyncze dodatkowe pobudzenia komorowe o innej morfologii, tj. prawogram z blokiem prawej odnogi pęczka Hisa (RBBB, right bundle branch block). W wykonanym kontrolnie badaniu EKG metoda Holtera zarejestrowano pojedyncze dodatkowe pobudzenia komorowe w liczbie $3,717 /$ dobe (tj. $4 \%$ rytmu dobowego). Chory nie wyraził zgody na zabieg by-passografii ani na proponowane wszczepienie kardiowertera-defibrylatora (ICD, implantable cardioverter-defibrillator).

\section{Podsumowanie}

Opisany przypadek ukazuje, jak ważne jest wyposażenie pracowni elektrofizjologii w wyrafinowane systemy elektro-
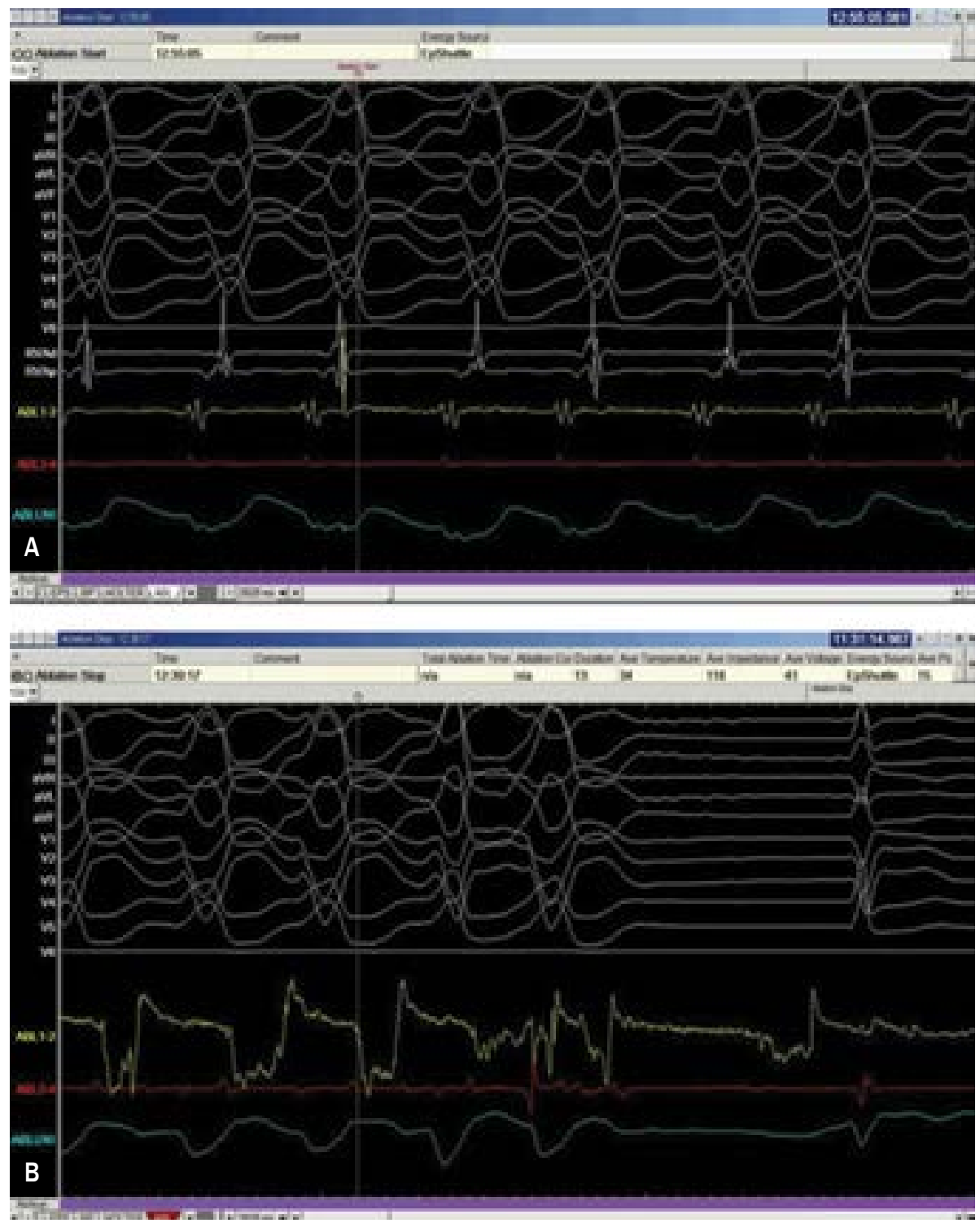

Rycina 6A. Potencjały zarejestrowane w płatkach aortalnych; B. Skuteczna aplikacja energii prądem o częstotliwości radiowej (RF, radiofrequency) i zanik arytmii 


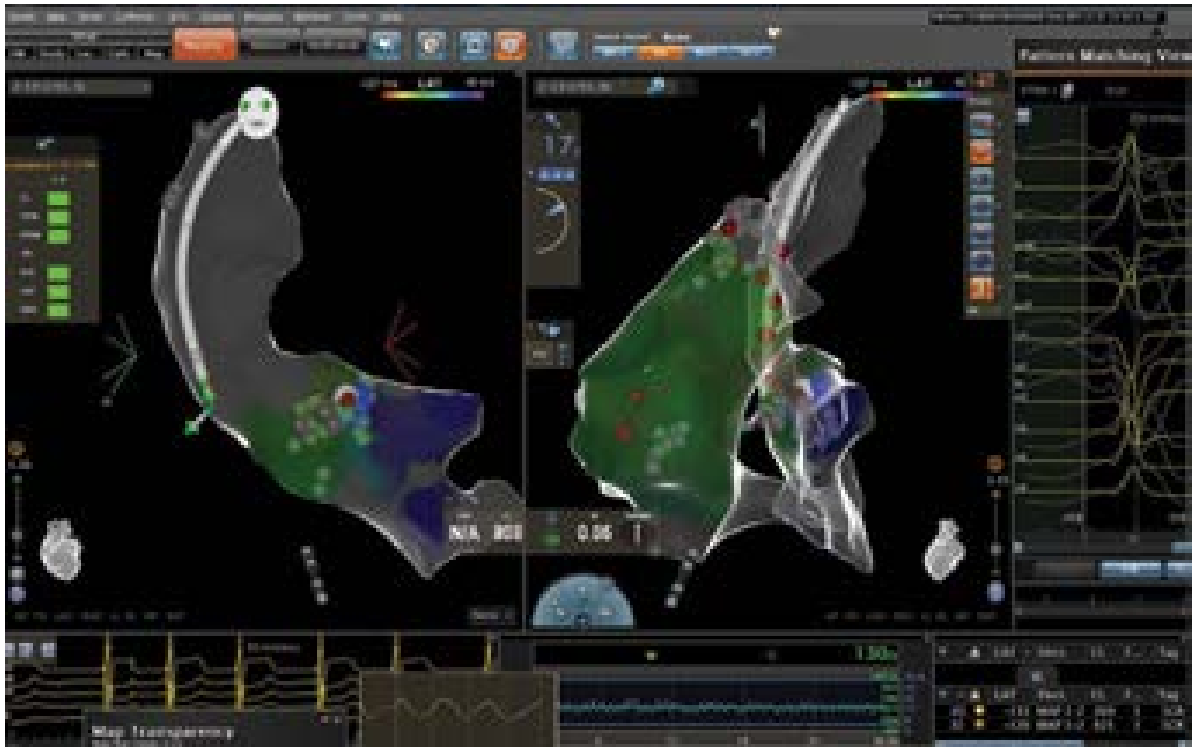

Rycina 7. Widok nałożonych na siebie map drogi odpływu z prawej komory/opuszka aorty z systemu Carto3 wraz z miejscami aplikacji

fizjologiczne i elektroanatomiczne, choć oczywiście żaden z nich nie zastąpi lekarza i jego zwykłej ,,analogowej” oceny odprowadzeń wewnątrzsercowych. Stanowi również kolejny argument w dyskusji o tym, że warto rozważyć u takich pacjentów ablację jako leczenie pierwszego rzutu usuwające substrat arytmogenny, tym bardziej że po skutecznym zabiegu u pacjenta wyeliminowano przynajmniej jedno ze wskazań do implantacji ICD. Być może, wykonanie opisanego zabiegu spowoduje, że żadne ze wskazań do wszczepienia ICD nie będzie już aktualne.

\section{Konflikt interesów}

Autorzy deklarują brak konfliktu interesów.

\section{Abstract}

A case of 68-years-old male with sustained ventricular tachycardia resistant to pharmacological therapy with multiple cardiovascular diseases, after cardiosurgical mitral valve replacement and left internal mammary artery to left anterior descending coronary artery bypass, atrial fibrillation, mildly reduced ejection fraction of heart failure. A description of diagnostics step by step and invasive treatment in patient with multiple risk factors of cardio-vascular incidents.

Key words: sustained ventricular tachycardia, anti thrombotic treatment, mapping, ablation

Folia Cardiologica 2018; 13, 1: 64-69

\section{Piśmiennictwo}

1. Priori SG, Blomström-Lundqvist C, Mazzanti A, et al. Wytyczne ESC dotyczące postępowania u pacjentów z komorowymi zaburzeniami rytmu oraz zapobiegania nagłym zgonom sercowym w 2015 roku. Kardiol Pol. 2015; 73(10): 795-900, doi: 10.5603/kp.2015.0190.
2. Ouyang F, Fotuhi P, Ho SY, et al. Repetitive monomorphic ventricular tachycardia originating from the aortic sinus cusp: electrocardiographic characterization for guiding catheter ablation. J Am Coll Cardiol. 2002; 39(3): 500-508, indexed in Pubmed: 11823089. 